\title{
O desejo homossexual após a AIDS: uma análise sobre os critérios acionados por homens na busca por parceiros do mesmo sexo
}

\author{
Homosexual desire after AIDS: an analysis of the criteria adopted \\ by men in the search for same sex partners
}

João Paulo Ferreira (https://orcid.org/0000-0003-0115-9032) ${ }^{1}$

Richard Miskolci (https://orcid.org/0000-0002-6405-5591) ${ }^{2}$

${ }^{1}$ Departamento de Sociologia, Universidade Federal de São Carlos. Rod. Washington Luiz s $/ \mathrm{n}$. 13565-905 São Carlos SP Brasil. joaopauloferreira@ outlook.com

${ }^{2}$ Universidade Federal de São Paulo. São Paulo SP Brasil.

\begin{abstract}
This article analyzes changes and continuities in partner search criteria by homosexual men considering the impact of the HIV-AIDS epidemic in the city of São Paulo, Brazil. Thus, it compares two different historical moments: between 1979 and 1981 (pre-epidemic) and 2015 to 2017 (post-epidemic). In the first period, the source incorporated 120 classified ads collected from the Lampião da Esquina newspaper and in the second period, the preferences and criteria used to search for partners were analyzed using geolocalized applications, based on 120 online profiles. The data show that that between 19791981 the search for "discreet" partners took place, while the sexual panic created in the deadliest period of the AIDS epidemic boosted the use of the Internet in search of partners less likely to be infected with HIV, the "out of the (gay) scene". Since then, the search for "discreet and out of the (gay) scene" has consolidated itself by shaping the body's ideals and conduct that shape the current São Paulo online sex market in which part of the homosexuals take part.
\end{abstract}

Key words HIV-AIDS, Internet, Male homosexuals, Hookup apps, Masculinities
Resumo Este artigo analisa as mudanças e continuidades nos critérios de busca de parceiros por homens homossexuais a partir do impacto da epidemia de HIV-aids na cidade de São Paulo. Assim, compara dois momentos históricos distintos: entre 1979 e 1981 (pré-epidemia) e 2015 a 2017 (pós-epidemia). No primeiro período, a fonte incorporou 120 classificados recolhidos do jornal Lampião da Esquina e no segundo período, foram analisadas as preferências e os critérios acionados na busca por parceiros realizada com o uso de aplicativos geolocalizados, a partir de 120 perfis on-line. Os dados permitem afirmar que, já na virada da década de 1970 para a de 1980, existia a busca pelo "discreto" enquanto o pânico sexual criado em meio ao período mais mortal da epidemia de AIDS impulsionou o uso de Internet por homossexuais em busca de parceiros com menor probabilidade de estarem contaminados com o HIV, o "fora do meio (gay)". Desde então, a busca pelo "discreto e fora do meio" se consolidou moldando ideais corporais e de conduta que regem o atual mercado sexual on-line em que se insere parte dos homossexuais paulistanos.

Palavras-chave HIV-aids, Internet, Homossexualidades masculinas, Aplicativos de busca de parceiros, Masculinidades 


\section{Introdução}

"Sou discreto e fora do meio" e suas variações, é uma apresentação corrente nos perfis on-line de homens que buscam parceiros do mesmo sexo nos atuais aplicativos geolocalizados que rodam em smartphones. Qual a origem dessa autodefinição que aparece também designando o parceiro ideal almejado? Resposta que, de antemão, sabese envolver o impacto que o período mais mortal da epidemia de HIV-aids (1981-1996) teve na vida sexual e amorosa de homens homossexuais ${ }^{1}$. Dessa maneira, este artigo tem por objetivo analisar comparativamente dois momentos históricos distintos: o primeiro deles situado entre 1970/1980 e o segundo no momento atual.

A pesquisa se assenta em uma compreensão histórica e sociológica do desejo homossexual masculino. Aqui o desejo é compreendido como motor cultural da busca por parceiros sexuais e/ ou amorosos. Afastamo-nos, assim, de interpretações que conferem ao desejo um caráter inato, atemporal e biológico, e nos vinculamos a uma perspectiva sociológica sobre o desejo que se insere em uma linhagem analítica já consolidada em que o define como socialmente construído, variando historicamente e segundo cada contexto social $^{2-6}$. No caso do desejo homossexual masculino em pauta, buscamos fontes documentais históricas e contemporâneas para compreender como a dinâmica individual de busca por parceiros permite analisar forças sociais, portanto coletivas, que moldam - de forma quase invisível - a esfera dos afetos.

Dentre as forças sociais que modificaram as buscas por parceiros por homens homossexuais paulistanos, destacamos o impacto cultural da epidemia de HIV-aids, portanto não a epidemia em si, antes a forma como ela passou a moldar os temores e os desejos em uma época em que a homossexualidade se tornou quase sinônimo de AIDS. A epidemia tem uma história, a qual pode ser dividida em períodos, dentro dos quais consideramos factível, a partir de Pelúcio e Miskol$\mathrm{ci}^{7}$, caracterizar - grosso modo - os anos entre o primeiro caso notificado oficialmente de AIDS (1981) até a invenção do coquetel antirretroviral (1996) como aquele em que o HIV e a AIDS eram hegemonicamente compreendidos como sinônimos devido à baixa eficiência do tratamento disponível. Naquele período, ser diagnosticado como HIV positivo era visto como uma "sentença de morte", daí o estigma da soropositividade ser ainda maior do que em nossos dias, algo perceptível na predominância de então do termo "aidético".
O estigma da soropositividade não foi superado por completo até hoje, mas é inegável que a distribuição gratuita do coquetel antirretroviral pelo Programa Nacional de AIDS, desde 1997, e a melhora efetiva da condição de vida ${ }^{8}$ dos soropositivos aplacaram, pouco a pouco, o pânico sexual que caracterizou a década de 1980 e o início da seguinte. De qualquer forma, o que os dados coletados em nossa pesquisa indicam é a continuidade do impacto do pânico sexual entre homens paulistanos que buscam parceiros do mesmo sexo. Tal continuidade, buscaremos argumentar, se dá de forma frequentemente indireta e, portanto, pouco perceptível para os sujeitos, o que não significa que seja algo secundário ou menos poderoso na definição dos critérios acionados para buscar parceiros amorosos e sexuais.

Nos resultados e discussão, iniciaremos apresentando os dados históricos obtidos por meio da pesquisa com os classificados de busca de parceiros no jornal O Lampião da Esquina (1979-1981), reconhecida publicação voltada para o público homossexual que surgiu após a abertura política do final da ditadura militar (1964-1985). Em seguida, analisaremos os perfis que colhemos em anos recentes por meio de um dos aplicativos de busca de parceiros geolocalizados mais populares entre os homens paulistanos que buscam parceiros do mesmo sexo. Depois, contrastaremos nossas fontes de maneira a identificar as mudanças e as permanências nos critérios que moldam a busca por parceiros no contexto paulistano, portanto trazendo elementos históricos e culturais para compreender sociologicamente o desejo homossexual masculino nas últimas décadas. Por fim, a título de conclusão, identificaremos alguns aspectos que auxiliam a compreender o impacto cultural contínuo que a epidemia de HIV-aids legou à esfera afetiva de homens paulistanos contemporaneamente.

\section{Metodologia}

O estudo caracterizou-se como transversal, de natureza mista, agrupando métodos e técnicas quantitativas e qualitativas ${ }^{9,10}$. Para o primeiro momento, com o jornal Lampião da Esquina, foi empregada a análise documental das colunas Cartas na Mesa e Troca-Troca, veiculadas entre abril de 1978 e junho de 1981.

Nesta etapa, analisamos as 38 edições do jornal, incluindo a número zero. Por conseguinte, foram coletados os anúncios nas duas colunas supracitadas, seguindo o recorte/critério pré-de- 
limitado: homem, de qualquer faixa-etária e residente na cidade de São Paulo.

$\mathrm{Na}$ segunda etapa, que compreendia o recolhimento e análise de perfis on-line, utilizamos o aplicativo Hornet $^{\circledR}$ como ferramenta para tratar dos anos de 2015 e 2016. O aplicativo funciona como uma rede social georreferenciada voltada para homens gays, bissexuais e curiosos, conforme a interface comercial o apresenta, com versão gratuita e paga. Segundo dados disponibilizados on-line pela Hornet Networks Limited, o aplicativo aglutina mais de 25 milhões de usuários globalmente, sendo que destes, pouco mais de 5 milhões são brasileiros. A escolha pelo Hornet ${ }^{\circledR}$ justifica-se, principalmente, pela grande abrangência do aplicativo nos circuitos de paquera $e$ busca sexual/amorosa entre homens homossexuais em São Paulo, conforme demonstrado por Miskolci ${ }^{6}$, além da possibilidade de recrutar informações detalhadas acerca dos perfis sem necessariamente haver a necessidade de se obter um perfil pago.

Nesta etapa, criamos um perfil como pesquisador dentro da plataforma para estabelecer o campo e observar como as pessoas dentro do recorte acima textualizavam o perfil e visibilizavam caracteres, imagens e recursos variados. Adotamos o lurking ${ }^{11}$ como técnica, o qual envolve a possibilidade de pesquisar de maneira observacional e não interativa, recolhendo dados da plataforma que permitam conceber uma amostra de uma dada população/grupo estabelecida on-line. A técnica não é nova para as ciências sociais, podendo ser também descrita como "observação on-line não participante", uma vez que o pesquisador não interage diretamente com os interlocutores, valendo-se de dados públicos disponibilizados nos perfis, a fim de agrupar informações qualitativas sobre a amostra. Foram coletados 120 perfis de usuários homens residentes na cidade de São Paulo.

A pesquisa foi financiada pela Fundação de Amparo à Pesquisa do Estado de São Paulo e segue as prerrogativas éticas previstas pelo Conselho Nacional de Saúde ${ }^{12}$, aprovada pelo Comitê de Ética em Pesquisa com Seres Humanos, da Universidade Federal de São Carlos.

\section{Resultados e discussão}

"MORENO, 25 anos, discreto, bonito, deseja corresponder-se com rapazes entre 18 e 23 anos que sejam ativos e discretos". São Paulo, Março de 1981. Lampião da Esquina, edição 34.
Este é um dos anúncios de busca de parceiros da então recém-criada coluna Troca-troca. Ao longo da pesquisa documental, nos deparamos com mais de uma centena de perfis semelhantes ao apresentado. Era lugar-comum nos anúncios a preferência por alguém "discreto", que fosse "jovem" - compreendendo uma faixa etária dos 18 aos 25 anos -, "bonito" e "ativo". Além disso, uma grande parcela dos anunciantes se apresentava como "discreto", "moreno", "bonito", "entendido" e "jovem" (Figura 1). A média de idades entre os anunciantes foi de 24,69 anos, o que corrobora a preferência por pessoas de faixa-etária semelhante ou mais jovens.

Usamos os termos entre aspas por duas razões: são termos descritivos êmicos e também porque, mais adiante, os utilizaremos para construir categorias analíticas que permitam discutir sociologicamente o que elas nos revelam sobre as homossexualidades masculinas na cidade de São Paulo daquela época. Posteriormente, por meio da comparação com os termos acionados atualmente nos aplicativos de busca de parceiros, tais categorias nos auxiliarão a compreender as dinâmicas relacionais do presente.

Depreende-se da Figura 1, assim, uma síntese das descrições pessoais encontradas nos anúncios de busca de parceiros a partir dos classificados. Há, evidentemente, três descritores que se sobressaem em relação aos demais, sendo estes: "discreto", "moreno" e "entendido".

O "discreto", em meio à Ditadura Militar, pode ser compreendido como uma característica de reação frente a uma sociedade conservadora e heterossexista em que sujeitos que se interessavam pelo mesmo sexo e relacionavam-se em espaços comuns buscavam performar uma masculinidade insuspeita, ou seja, que não os denunciasse como homossexuais no espaço público que, então, era sinônimo de heterossexualida$\mathrm{de}^{6}$. De início, o termo também parecia resolver provisoriamente os paradoxos representacionais disponíveis nos semanários e folhetins que circularam antes do Lampião (O Snob, Le Femme, Os Felinos e Okzinho), quer seja pela oposição hierárquica compreendida entre "bichas/bonecas" e "bofes", quer seja em relação à posição sexual assumida nos relacionamentos, frequentemente estabelecida entre sujeitos socialmente identificados como "ativos" ou "passivos" - esta última característica associada à feminilidade ${ }^{13,14}$.

Guimarães ${ }^{15}$ e Perlongher ${ }^{16}$ apresentam, em termos etnográficos, que os usos e a elevada demanda pela discrição estavam relacionados com a hostilidade vigente no espaço público em re- 


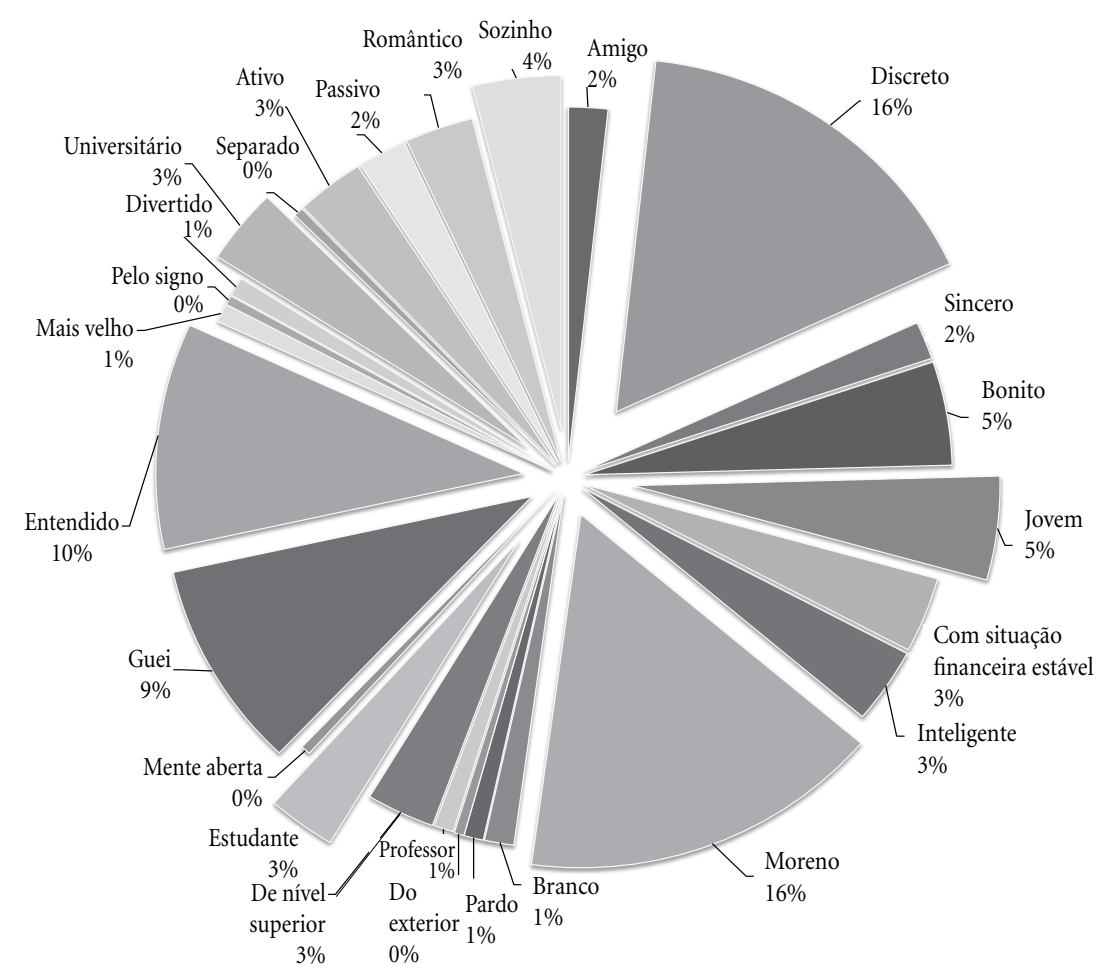

Figura 1. Descrição pessoal por categorias acionadas, em números absolutos, com repetição. São Paulo, 19791981.

Fonte: Banco de dados produzido pelos autores.

lação às homossexualidades, cujas formas de paquera e busca de parceiros desenvolveram-se associando o medo da violência e da perseguição, além de eventual descoberta e recusa por pessoas próximas, incluindo as redes de amigos, colegas de trabalho e familiares. As buscas, entre os anos 1970 e 1980, ocorriam em territórios de sociabilidade face a face, os quais reuniam sujeitos de diferentes classes sociais, origem étnico-racial, entre outras características. Os banheiros públicos, cinemas, praças, parques, estacionamentos e ruas comerciais, especialmente no período noturno, se tornaram espaços destinados ao flerte e à paquera, os chamados territórios de "pegação", isto é, lugares afeitos à busca por parceiros anônimos para sexo sem compromisso ${ }^{16}$.

Era frequente o risco de violência e perseguição nestes espaços, além da incisiva retaliação policial em fins do período militar; segundo Simões e França ${ }^{17}$, surgiram, a partir de 1976, em São Paulo, casas noturnas e boates destinadas a um público diversificado, além de bares que se organizavam principalmente nas regiões cen- trais, cuja proximidade com os já conhecidos territórios utilizados para as buscas reuniu um circuito amplo de sujeitos homossexuais e simpatizantes. Esses novos territórios, segmentados por classe social, gênero, sexualidade, geração e raça/etnia, criaram novas dinâmicas relacionais, atraindo "curiosos", que partilhavam das redes de "pegação", amizade e dos códigos próprios estabelecidos no meio homossexual paulistano ${ }^{16,17}$.

É neste período que ganha visibilidade a categoria "entendido/a". O/a "entendido/a", contudo, não foi uma categoria nova, sendo utilizado amplamente por mulheres lésbicas e homens homossexuais, desde os anos 1940, como uma espécie de correspondente ao "sujeito de mente aberta" ${ }^{15}$. Não obstante, o termo também evoca dois outros sentidos, pois, primeiramente, para muitos sujeitos que se reconheciam como desejantes pelo mesmo sexo, as categorias disponíveis pareciam demasiadamente grosseiras e depreciativas, especialmente para homens, cristalizando-se em apelidos vexatórios como "bicha" ou "veado"; em segundo lugar, o termo "entendi- 
do/a" serviu como categoria estratégica na qual o sentido visava desmanchar as dicotomias entre "boneca/bofe" e "ativo/passivo", nivelando, aparentemente, a suposta hierarquia sexual existente entre sujeitos homossexuais ${ }^{13,15}$.

Outra categoria prevalente é a composta por sujeitos autodeclarados "morenos", a qual poderia - à primeira vista - evocar uma noção racializada e, em certa medida, hibridizada, a respeito da corporalidade e do desejo. Mas devido às características socioeconômicas dos leitores do jornal em que se colheram os anúncios, ou seja, homens com grau elevado de escolarização e residentes em regiões valorizadas da cidade de São Paulo, também se pode inferir que o sujeito "moreno" seja uma referência a cabelo escuro e/ ou tez bronzeada, representando sensualidade e um tipo físico popular entre as classes-médias profissionais brasileiras, e não necessariamente a busca de um parceiro negro.

Os usos da categoria "moreno", ainda, podem estar relacionados às representações então correntes de homens considerados atraentes, muitas vezes veiculadas pelo próprio Lampião para seu público segmentado homossexual, mas também aquelas que apareciam nas mídias de massa da época, convergindo a racialização e a sexualização dos corpos. A construção da imagem pessoal é sempre um empreendimento relacional e coletivo, logo as descrições utilizadas pelos classificados refletem um processo de construção de si que passa pelo que é disponibilizado imageticamente como referência por meio das mídias de massa no Brasil, além das características específicas demandadas pelos usuários dos anúncios de busca por parceiros do mesmo sexo.

A partir da fonte documental pesquisada, a combinação destes três descritores - "moreno", "discreto" e "entendido" - permite-nos compreender sob quais inteligibilidades e formas de reconhecimento o desejo entre homens se estabelecia. As descrições sobre si e as preferências demandadas nos anúncios reiteravam expectativas sociais, a fim de modelar e reproduzir, de maneira simbólica, as representações valorizadas acerca da masculinidade e do desejo. Deste modo, os três descritores, em diálogo, intermediaram uma gramática de recusa daqueles parceiros que pudessem ser reconhecidos publicamente como homossexuais - supostamente "afeminados" -, também como passivos ou, ainda, como "bichas" ou "bonecas", privilegiando sujeitos "entendidos", os quais possivelmente não seriam identificados no espaço público como homossexuais, evitando discriminações e violências.
No que toca às preferências acionadas, emerge também a categoria "amizade", seguida pelo já comentado "discreto", que se associava a pessoas de "todos os tipos" e predominantemente "jovens", como se pode concluir pela Figura 2.

O fato das preferências aglutinarem uma busca por "amizade" reforça nossa análise sobre os outros descritores acionados nos anúncios: a de que o parceiro ideal buscado não expressava apenas gostos pessoais, mas também a demanda social corrente por discrição e manutenção de uma heterossexualidade presumida no espaço público.

Nestes termos, a busca por "amizade" podia indicar o desejo por não ser reconhecido publicamente com um parceiro do mesmo sexo, o que exporia sua orientação sexual no cotidiano. Houve ainda a incidência da categoria "discreto", quase que na mesma proporção da categoria "amizade", o que nos permite inferir que ambas são acionadas com expectativas semelhantes em relação ao parceiro ideal e, indiretamente, da forma que se esperava viver a homossexualidade: sem chamar a atenção no espaço público, na família ou no trabalho.

A categoria "jovem", por outro lado, pode ser compreendida como uma representação tanto descrita e, portanto, materializada na descrição pessoal dos anunciantes, quanto demandada. Apesar da média das idades dos homens que anunciavam nas colunas ter sido 24,69 anos, havia muitos anúncios de sujeitos mais velhos, cujas idades revelam os intercursos geracionais dos circuitos de paquera e busca amorosa no jornal. Do ponto de vista das relações, havia dois aspectos comuns que convergiam: a preferência por juventude e masculinidade. Os sujeitos mais velhos, argumenta Perlongher ${ }^{16}$, conseguiam burlar a ausência de um ethos jovem por meio do capital econômico, propiciando recompensas materiais e simbólicas aos parceiros. E os parceiros, em contrapartida, personificados por uma estética jovem e masculinizada, comodizavam sua masculinidade "crua" e "autêntica" - proveniente do imaginário social em relação às classes -baixas - em troca de capital econômico.

As práticas sexuais e de busca por parceiros entre homens, em termos culturais, entretecem representações de sexo (corpo) e de gênero (masculinidades) específicas ${ }^{18}$. Uma vez que o "corpo" e as "masculinidades" adquirem significados socialmente construídos, haverá um processo contínuo de criação e transformação de tipos ideais dentro daquilo que é valorizado em meio ao vocabulário hegemônico da masculinidade (heterossexual) disponível ${ }^{19}$. 


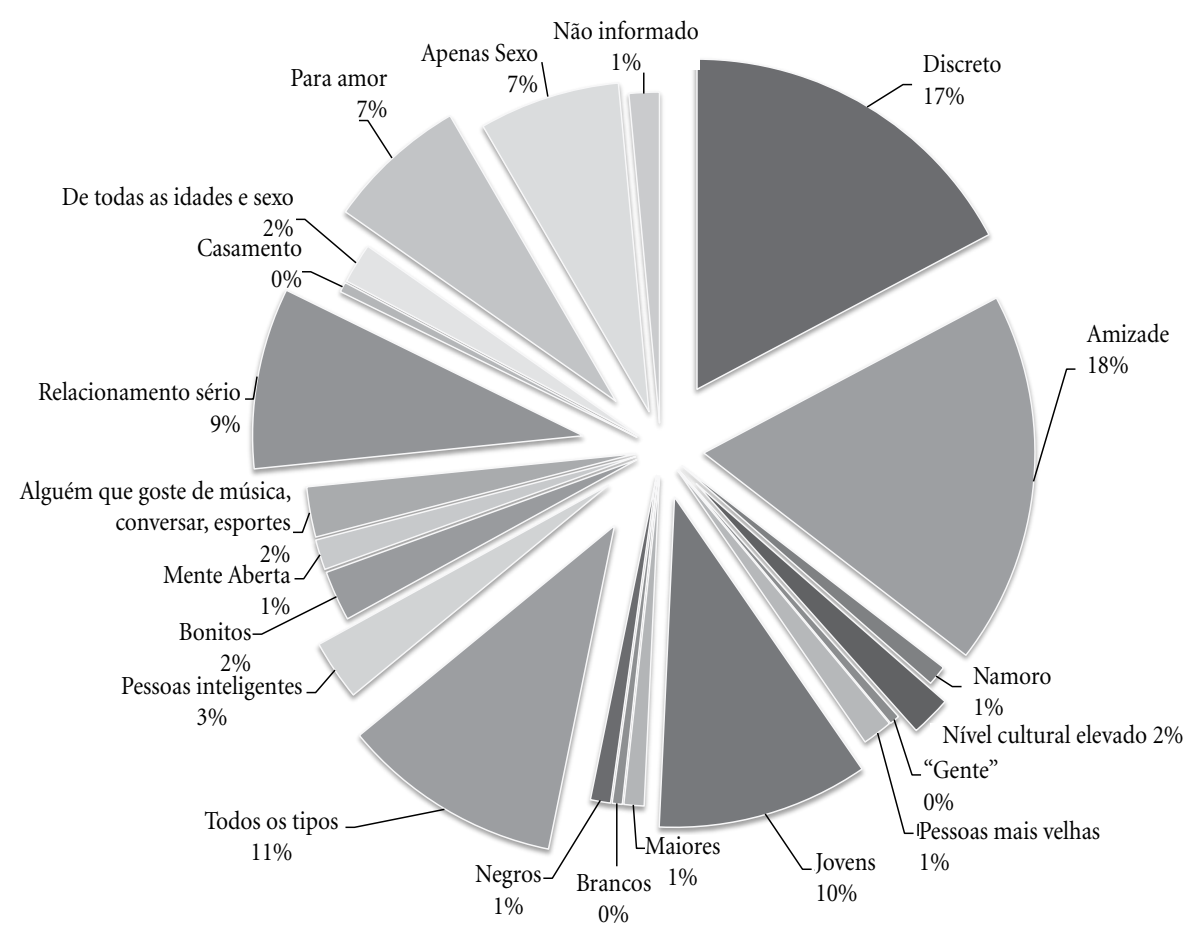

Figura 2. Preferências acionadas nos classificados, em números absolutos, com repetição. São Paulo, 1979-1981.

Fonte: Banco de dados produzido pelos autores.

A partir dos descritores acionados pelos anunciantes nos classificados de jornal, é possível constatar que as representações demandadas entre homossexuais paulistanos, em fins dos anos 1970 e início dos anos 1980, para a construção de seu par ideal, uniam categorias como "discreto", "entendido", "moreno" e "jovem", par com o qual viveriam relações amorosas e/ou sexuais insuspeitas, as quais poderiam ser vistas socialmente como "amizade".

\section{A nova economia digital do desejo: "discreto", "sarado" e "fora do meio"}

"Sou ativo, 25 anos, branco, $1.86 \mathrm{~cm}, 75 \mathrm{~kg}$, sarado e discreto, e busco caras que sejam também discretos e fora do meio. Se você for afeminado, nem perca seu tempo! Não respondo fantasmas, não venha sem foto! Sem enrolação, se eu não responder é porque não curti". São Paulo, Dezembro de 2016, Aplicativo Hornet ${ }^{\circledR}$.

Neste momento, nos debruçamos nos perfis recolhidos durante a pesquisa com mídias digitais, por meio do aplicativo Hornet ${ }^{\circledR}$, entre 2015 e 2016. De modo análogo à análise proposta para os classificados, nos deparamos com demandas que constituíam permanências e rupturas relativas aos critérios e preferências acionadas. Começando pela descrição pessoal, nota-se, a partir do perfil de um dos interlocutores da pesquisa reproduzido acima, seu detalhismo.

Isso se deve, em grande medida, devido ao formato e à estrutura arquitetural do aplicativo, que permite uma maior caracterização das informações, as quais buscam definir imagética e subjetivamente seus usuários materializando-os como um perfil on-line. A partir deste ponto, consequentemente, há a convergência de características objetivas e subjetivas, em que as primeiras podem ser sintetizadas nos descritores de "raça/ cor", "altura", "idade" e "peso", já pré-configurados nas plataformas digitais, levando seus usuários a escolherem dentre as opções aquelas que melhor correspondam às características físicas $\mathrm{e}$ corporais, preenchendo seus perfis com dados de si e atribuindo materialidade à sua persona digital. Zago ${ }^{18}$, neste aspecto, analisa que o conjunto de informações delimitadas possibilita a constru- 
ção de uma espécie de "currículo" sobre si, o que envolve a produção de corpos, masculinidades e sexualidades possíveis, habitáveis e negociáveis.

A caracterização subjetiva, por outro lado, materializa-se por meio dos descritores "sarado", "discreto", "fora do meio", "não afeminado" etc., cujos modelos e parâmetros de representação apóiam-se nas vivências dos interlocutores com as mídias, nas experiências com outros usuários e na adoção de modelos corporais e de masculinidades anteriormente reproduzidas nas mídias de massa e segmentadas - em especial na propaganda e na pornografia dirigida a homossexuais ${ }^{6,20}$.

No que concerne às descrições objetivas disponibilizadas pelos aplicativos e acionadas pelos usuários, distinguimos cinco grupos: "raça/ etnia", "status de relacionamento", "procurando", "status sorológico" e disposição da "foto do perfil" (Tabela 1).

Constata-se, em primeiro lugar, uma prevalência de sujeitos autodeclarados "brancos" ( $\mathrm{n}=$ $72)$, seguido por "latinos" $(\mathrm{n}=14)$ e "pardos" (n =6) (Tabela 1). Diferentemente do que se passou nos classificados - em que não havia um critério específico a respeito do perfil racial/étnico com o qual os anunciantes poderiam se definir, prevalecendo o descritor "moreno" -, há uma maior delimitação das categorias raciais, incentivada pela interface da plataforma e que segue a configuração norte-americana de compreendê-las. Ainda a respeito das diferenças relativas aos classificados impressos do passado, é possível notar que nas plataformas digitais vigora um pré-enquadramento, de forma que os usuários são alocados em categorias que materializam racialmente o corpo e a subjetividade, racializando (ou não, no caso dos "brancos") a corporalidade e o desejo ${ }^{21}$.

Em segundo lugar, uma grande parcela dos perfis constituía-se por sujeitos autodeclarados "solteiros" ( $\mathrm{n}=94)$ e, em menor proporção, aqueles "numa relação aberta" $(\mathrm{n}=4)$ e "namo- rando" $(\mathrm{n}=4)$. Em relação à busca, houve uma prevalência de sujeitos que buscavam "encontros" $(\mathrm{n}=61)$, o que compreende encontros para sexo, seguido de "amizade" ( $\mathrm{n}=16)$ e "namoro" ( $\mathrm{n}=$ 11). No que diz respeito ao status sorológico, a maioria dos usuários preferia "não mostrar" ( $\mathrm{n}=$ 67) e, dentre os que descreviam seus status nos perfis, vê-se uma prevalência de "negativo" ( $\mathrm{n}=$ 30). A pouca exposição do status sorológico pode ser compreendida por meio do contraste com a realidade norte-americana estudada por Miskol$\mathrm{ci}^{\mathrm{6}}{ }^{6,22}$, na qual subsiste a escolha de parceiros pelo status sorológico que sociólogos como Kane Race ${ }^{23}$ caracterizam como serosorting, uma prática resultante de um modelo de prevenção focado no indivíduo e na ausência de um programa universal de saúde como o brasileiro. Se nos Estados Unidos a descrição do status sorológico se impõe, aqui - onde houve décadas de propaganda sobre sexo seguro como prática geral - ela se revela menos prevalente ou demandada. Não obstante, a exposição (ou não) do status sorológico não configura um empecilho à entrada no aplicativo, uma vez que tal informação não é obrigatória para o cadastro pessoal e, como vimos pelos dados, muitos interlocutores preferiram não informar.

Este dado permite contrastar os efeitos do pânico sexual da AIDS em contextos que não possuem tratamento público e universal de saúde. Recentemente, a ONG norueguesa SINTEF denunciou publicamente o aplicativo Grindr pelo vazamento de informações relativas ao status sorológico de seus usuários com as empresas Apptimized e Localytics. Segundo nota publicada pela BBC Brasil, em abril de 2018, a rede social "compartilhou a posição exata de GPS do usuário, sua tribo (com qual grupo do universo gay o dono do perfil mais se identifica), orientação sexual, status de relacionamento, etnia e telefone". O escândalo não deixa dúvidas de que a ética do desejo nas mídias digitais é revestida por de-

Tabela 1. Categorias expressas na interface dos perfis pelo aplicativo Hornet ${ }^{\circledR}$. São Paulo, 2015-2016.

\begin{tabular}{lcllclllll}
\hline \multicolumn{2}{l}{ Raça/etnia } & \multicolumn{2}{l}{ Status de relacionamento } & \multicolumn{2}{c}{ Procurando } & \multicolumn{2}{c}{ Status sorológico (HIV) } & \multicolumn{2}{c}{ Foto do perfil } \\
\hline Negro & 3 & Solteiro & 92 & Conversar & 8 & Não mostrar & 67 & Rosto a mostra & 53 \\
Latino & 14 & Enrolado & - & Encontros & 61 & Não sei & 1 & Rosto de lado & 2 \\
Árabe & 2 & Numa relação aberta & 4 & Amigos & 16 & Negativo & 30 & Peito e abdômen & 38 \\
Pardo & 6 & Namorando & 4 & Networking & 4 & Positivo & 1 & Quadril (pênis) & - \\
Asiático & 3 & & & Namoro & 11 & Negativo, em PrEP* & - & Quadril (bumbum) & 1 \\
Branco & 72 & & & & & Positivo, indetectável & 1 & De costas & 6 \\
\hline
\end{tabular}

Fonte: Banco de dados produzido pelos autores.

* Profilaxia pré-exposição. 
mandas pessoais, insegurança, medo de contaminação - explicitamente em contextos nos quais o acesso à saúde não provém de uma política pública comum -, especulação mercadológica e novas concepções de risco e prevenção.

Além disso, a maior parte dos perfis vinha acompanhada de uma foto com o rosto à mostra $(\mathrm{n}=53)$, seguido das regiões do peito e abdômen $(\mathrm{n}=38)$ e de costas $(\mathrm{n}=6)$. A idade, em terceiro lugar, aponta uma prevalência de pessoas na faixa-etária dos trinta aos quarenta e cinco anos, sendo que a média foi de 39,37 anos - aproximadamente quinze anos a mais do que fora encontrado no jornal (24,69 anos). Nestes termos, é possível observar uma grande diferença geracional nas duas fontes de pesquisa analisadas.

É preciso considerar, antes de qualquer coisa, as distinções que abrangem as duas mídias: na primeira, em fins dos anos 1970, havia a necessidade de escolarização básica para se ter acesso aos classificados e também para enviar cartas à redação do jornal, o que contrasta com a realidade brasileira do período, uma vez que em 1980 o número absoluto de pessoas analfabetas somava 32,7 milhões ${ }^{24}$. Além disso, em termos de escolarização, havia desigualdades severas entre as cinco regiões do país na época. Este fato nos leva a considerar que, por se tratar da cidade de São Paulo, com indicadores melhores comparativamente aos outros estados, o dado relativo à idade pode ter tido um saldo positivo em relação às demais regiões.

Na segunda mídia, há uma situação social e histórica distinta, a começar pela mudança da pirâmide demográfica nacional causada pelo aumento da expectativa de vida e a diminuição do número de jovens na população total. Além disso, o número de pessoas analfabetas no país era de 7,2\% em 2017, de acordo com a Pesquisa Nacional por Amostras de Domicílio (PNAD/IBGE), atingindo apenas 3,8\% na região Sudeste ${ }^{25}$.

Estes dados referentes à "raça/cor", "status de relacionamento", "status sorológico" e "idade", expressos na interface dos perfis coletados mostram uma nova maneira de se descrever e, a propósito, também provam uma intensificação das descrições, dos classificados aos aplicativos. Eva Illouz $\mathrm{z}^{4}$ analisa que esse processo de constituição de um perfil on-line é produto de uma avaliação meticulosa de si e do próprio desejo: a descrição requer uma estimativa rigorosa entre aquilo que é objetivo e aquilo que é subjetivo. Não há um limite estrito e explícito entre esses dois campos, mesmo porque são não se trata, evidentemente, de esferas apartadas.
Segundo Illouz ${ }^{4}$, Baym $^{26}$ e Sibilia ${ }^{27}$, as narrativas on-line ganham corpo em um contexto a partir do qual se é possível representar de muitas maneiras, quer seja pelo uso de linguagem escrita quer seja pelo conteúdo visual compartilhado, como é o caso das fotos. Os usos destes recursos, não mais como simples itens opcionais disponíveis aos usuários de aplicativos, funcionam como uma espécie de imperativos sociais à entrada bem-sucedida nas buscas e na sociabilidade digital, como reproduzido na fala de um dos interlocutores: Não respondo fantasmas, não venha sem foto!.

$\mathrm{O}$ valor simbólico atribuído às fotos permite criar um parâmetro entre o que fora descrito no perfil, em termos de linguagem textual, e aquilo que pode ser visto e, em certa medida, comprovado e tornado real. A imagem, em suma, funciona como uma "tecnologia de gênero" ${ }^{28}$, ao passo que ela tenciona percepções e sentidos coletivos de sexualidade e masculinidade, a fim de representar sujeitos e práticas, e atribuir forma, conteúdo e veracidade aos perfis criados on-line $e^{4,29,30}$.

Ainda em relação à descrição pessoal apontada pelos interlocutores, $18 \%$ descreviam-se como "ativos", 13\% como "discretos" e "passivos", $12 \%$ como "não afeminados" e $11 \%$ como "fora do meio (gay)" (Figura 3). Comparativamente, os dados permitem verificar permanências e rupturas tocantes aos anúncios nos classificados impressos de outrora. Das permanências, destacam-se os usos substanciais da categoria "discreto" que mantém o intuito de evitar a associação com uma performatividade "feminina" que denunciaria publicamente a homossexualidade em si e/ou no outro.

Os termos relativos às posições sexuais ganham maior visibilidade e, infere-se, maior importância na seleção de parceiros do que no passado. O termo "versátil", possível forma contemporânea do "entendido", aparece em menor proporção como alternativa aparentemente menos hierárquica e mais fluida (Figura 3).

Do ponto de vista da gramática do desejo, há também rupturas e, com isso, o aparecimento de categorias novas, a exemplo do sujeito "fora do meio (gay)". O termo, de acordo com a literatura, não data das mídias digitais, embora tenha se disseminado a partir delas, inserindo-se numa problemática social e histórica emergida entre 1986 e 1997 - período que compreende o auge das mortes pela epidemia de HIV-aids ${ }^{4,30}$.

Pelúcio e Miskolci ${ }^{7}$ discutem que, em fins dos anos 1980, a homossexualidade masculina foi repatologizada, deixando de ser vista como uma 


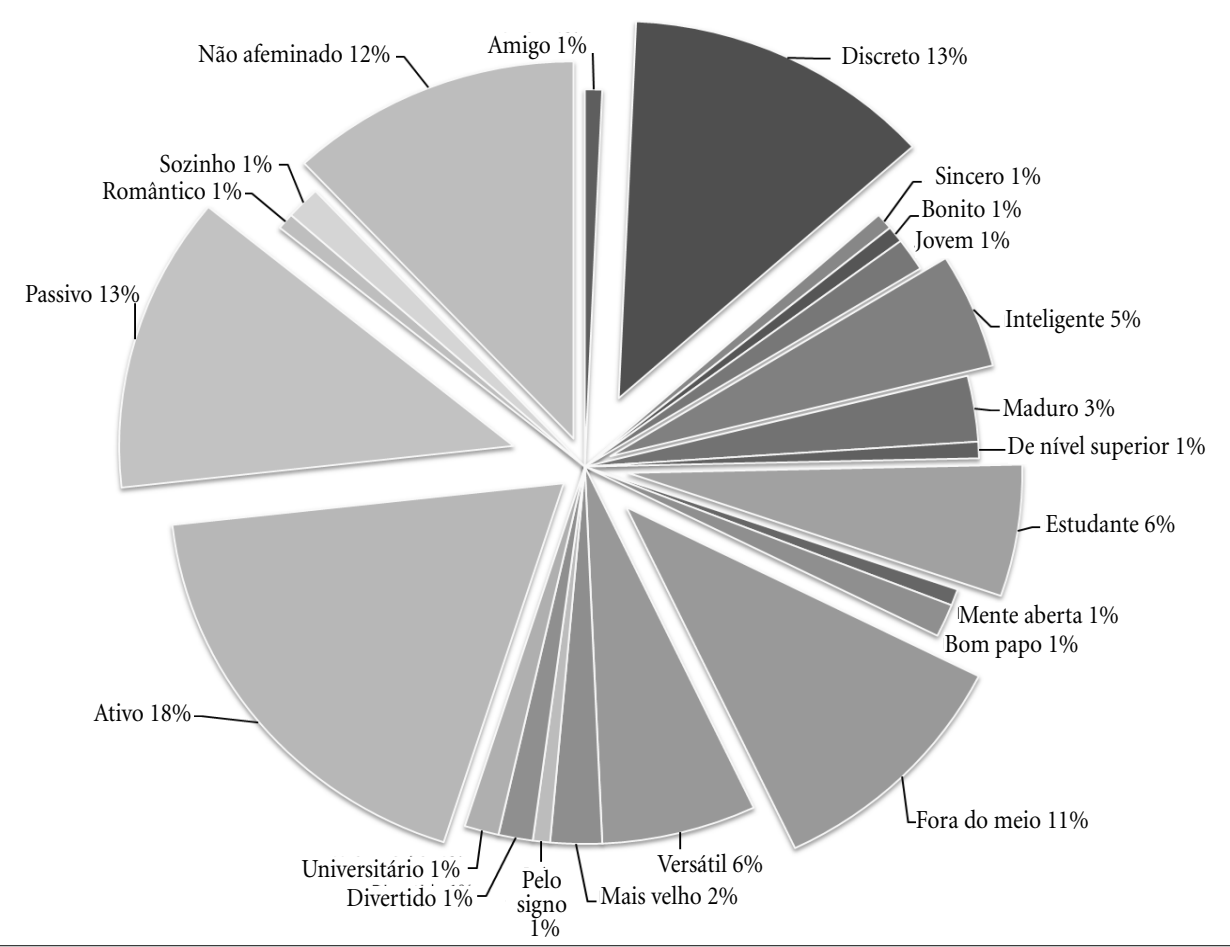

Figura 3. Descrição pessoal expressa na interface dos perfis pelo aplicativo Hornet ${ }^{\circledR}$. São Paulo, 2015-2016.

Fonte: Banco de dados produzido pelos autores.

doença mental para se tornar uma problemática epidemiológica. Isso, pois, no inicio da epidemia de HIV-aids, em meados de 1981 e 1983, não havia claro conhecimento a respeito da etiologia da doença, tampouco em relação aos fatores de risco e aos prováveis sinais e sintomas ${ }^{31,32}$. Assim, muitas especulações a respeito das vias de propagação do HIV-aids se estabeleceram, bem como discursos moralizantes. Esses discursos, oriundos de vertentes religiosas e da grande imprensa, acabaram por criar os chamados "comportamentos de risco" e, na mesma toada, os "grupos de risco"31-33.

Homossexuais, prostitutas, imigrantes haitianos e usuários de drogas endovenosas foram os primeiros grupos de risco demarcados pelo Centro de Controle de Doenças (CDC), nos Estados Unidos. A AIDS, tratada primeiramente por Deficiência Imunológica Relacionada à Homossexualidade - ou Gay Related Immune Deficiency (GRID) -, criou um pânico sexual generalizado, ora em decorrência do próprio desconhecimento etiológico e da impossibilidade de tratamento eficaz, ora em virtude da exposição que a descoberta da patologia poderia causar, uma vez que dizer-se "soropositivo", no contexto da época, seria análogo a dizer-se "homossexual"
"Data desse período, também, a emergência de um modelo corporal hegemônico, o do homem malhado ou "sarado", termo que evoca a ideia de que um corpo trabalhado por exercícios físicos seria a prova de saúde, de não estar doente, possivelmente não ter o vírus HIV. Na verdade, há pesquisas em diferentes contextos nacionais que afirmam que esses corpos musculosos foram criados como conseqüência da própria epidemia de AIDS, pois sem medicação efetiva, médicos receitavam esteróides e recomendavam a prática de musculação para evitar perda de peso e incentivar um estilo de vida "saudável" aos portadores do HIV"30.

A imagética do desejo homoerótico representada sob o prisma do modelo preventivo da AIDS permite reconstituir a junção de imperativos morais a questões de saúde coletiva, cristalizando socialmente a concepção de que sujeitos homossexuais corporalmente indisciplinados - leia-se: macilentos ou fora dos padrões hegemônicos da masculinidade - seriam doentes e, possivelmente, soropositivos. Por outro lado, os homens que se dedicavam aos esportes e, na década de 1980, faziam parte da chamada "Geração Saúde", materializariam o "sarado": "a disciplina corporal que 
envolve exercícios, dietas e hábitos supostamente saudáveis distancia esses homens de estereótipos ainda correntes de homossexuais como sem disciplina, desviantes sociais e adeptos de hábitos reprováveis ou perigosos" ${ }^{\text {"6 }}$.

Os novos termos, coletados a partir da pesquisa com mídias digitais, revelam razões históricas e sociais que induzem, inconscientemente, homens homossexuais a buscarem parceiros com um determinado perfil. Esse novo regime erótico constitui - on-line - uma "nova economia do desejo" ${ }^{\prime, 22}$, cuja visibilidade é mais perceptível quando se analisa os descritores e as categorias êmicas produzidas nas últimas três décadas, não somente em termos de "descrição pessoal", como vimos anteriormente (Figura 3), mas também em relação às demandas relativas ao parceiro em potencial, recuperadas a seguir como "preferências" (Figura 4).

As preferências mais acionadas pelos usuários do aplicativo são: "discreto" (17\%), "ativo" (11\%), "não afeminado" (10\%), "sigilo" (8\%), "fora do meio (gay)" (7\%), para "amizade" (7\%) e "másculo" (6\%) (Figura 4). Passados mais de
30 anos desde os anúncios impressos já analisados, ainda mantém-se vigentes critérios de seleção de parceiros que permitam a manutenção de uma heterossexualidade presumida no espaço público. O imperativo da busca continua a ser o afastamento de prováveis estigmas, quer seja pela partilha de códigos e formas de desejar socialmente reconhecidas quer seja pela recusa de pessoas com as quais os sujeitos seriam lidos publicamente como homossexuais.

Apesar de mais incipientes, comparativamente aos classificados, houve a incidência de buscas por "namoro", que se associavam - nos anúncios de jornal - à demanda por "relacionamento sério" e "amor", e no aplicativo à demanda por "sigilo", "pessoas mais velhas" e "alguém que goste de música, esportes ou conversar". Essa inferência, tomada a partir dos descritores e da média de idades nos dois contextos, nos leva à constatação de que a demanda por estabilidade e relacionamento duradouro se soma a um aumento de 14,69 anos em relação à idade, ao passo que os perfis no aplicativo são frequentemente de pessoas acima dos 30 anos.

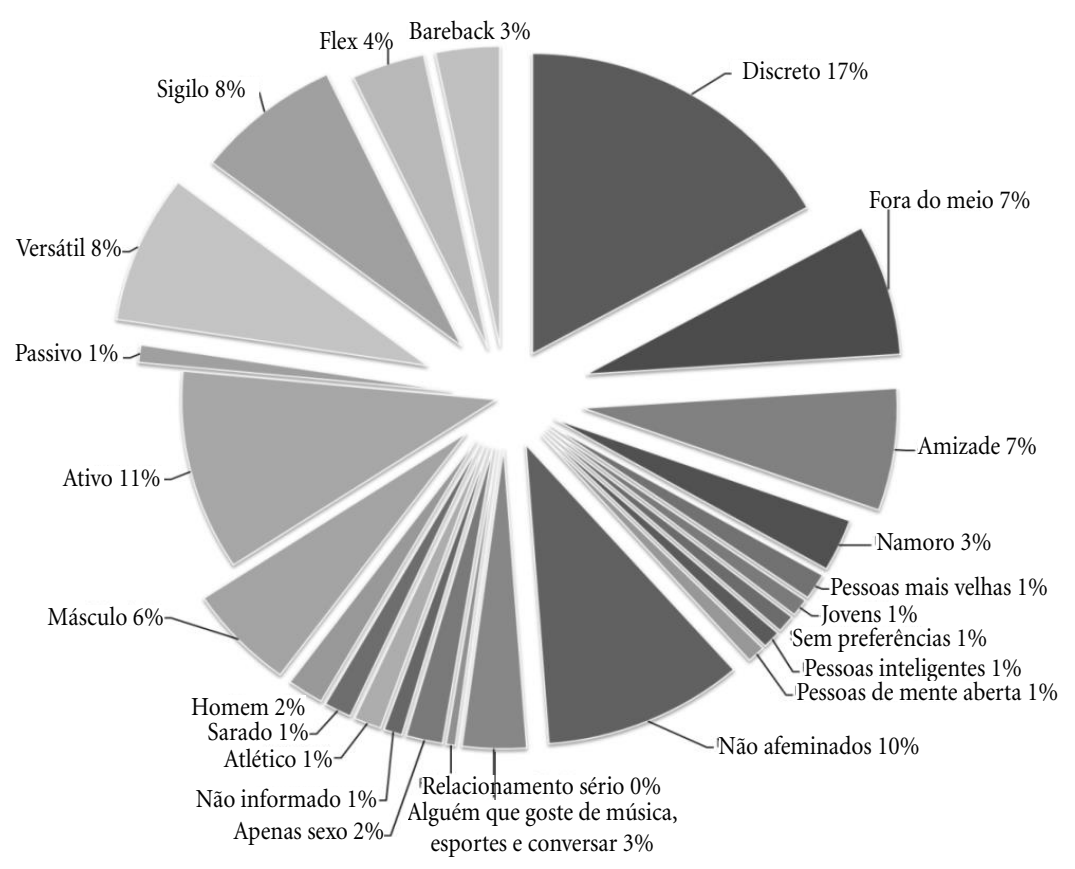

Figura 4. Preferências expressas na interface dos perfis pelo aplicativo Hornet ${ }^{\circledR}$. São Paulo, 2015-2016. 


\section{Considerações finais}

Historicamente, ao menos nos períodos e meios analisados, a busca de homens paulistanos por parceiros do mesmo sexo revela uma economia desejante moldada por expectativas de aceitação coletiva. Assim, buscam tanto um parceiro quanto uma relação que permitiriam afastar-se de estigmas sociais, o que cria uma lógica interativa nos aplicativos marcada pela competição pelos perfis socialmente mais reconhecidos assim como por relações em que se atribui ao(s) outro(s) as características das quais quer se afastar. Sob uma ordem social em que o reconhecimento, a segurança e os direitos ainda não são garantidos plenamente a homossexuais não é de se estranhar que os sujeitos busquem se apresentar, encontrar um parceiro e viver relações que pareçam/se aproximem da heterossexualidade.

O contraste dos dados coletados entre 1979 e 1981 e os entre 2015 e 2016 permite reconhecer continuidades, mas também algumas mudanças. A pobreza visual das publicações impressas da virada dos anos 1980 contrasta com a riqueza imagética dos aplicativos, atualmente. Ainda que os anúncios impressos não tivessem fotos, eles mostram uma menor ênfase na descrição corporal dos parceiros buscados e as fotos publicadas em outras seções de O Lampião provam que os modelos corporais e de beleza masculina no segmento homossexual eram distintos dos atualmente vigentes. Nos aplicativos, por sua vez, além das fotos dos usuários, há descrições detalhadas e criteriosas dos possíveis parceiros, revelando que os mais buscados tendem a corporificar o "discreto" e "fora do meio" volta e meia como o "sarado" - o homem jovem de corpo definido que foi alçado a ícone cultural gay no auge da epidemia de HIV-aids.

A nova economia desejante, isto é, as buscas nas mídias digitais interpretadas sob o prisma dos descritores coletados, revelam ainda a necessidade de sobrevivência e circulação em espaços comuns, ora pelo acionamento dos termos supracitados, a fim de se evitar estigmas e discriminações públicas, ora como uma estratégia de negação do desejo. Esta última consideração, no entanto, opera materializando uma espécie de recusa da categoria "homossexual", cuja articulação com os descritores permite entrever uma demanda por parceiros os quais, ao fim e ao cabo, sequer se compreendam como "gays" ou "homossexuais".

Na virada dos anos 1980, formas relacionais como o namoro e o casamento não faziam parte da gramática homossexual sendo compreensivelmente substituídas pelo encontro sexual anônimo ou a "amizade". Nos aplicativos atuais, além da demanda por amizade há também a incidência de buscas por relacionamentos amorosos e estáveis. Tal busca por amor, mesmo sendo percentualmente pequena (3\%), indica transformações no horizonte aspiracional de homens que buscam parceiros do mesmo sexo que podem estar relacionadas com o recente reconhecimento legal das uniões entre pessoas do mesmo sexo pelo Supremo Tribunal Federal, em 2011, e sua equivalência ao casamento, em 2013.

\section{Colaboradores}

R Miskolci trabalhou na concepção da pesquisa, coleta de dados, revisão crítica e redação do manuscrito; JP Ferreira trabalhou na concepção da pesquisa, coleta de dados, revisão crítica e redação do manuscrito.

\section{Agradecimentos}

Agradecemos à Fundação de Amparo à Pesquisa do Estado de São Paulo pelo financiamento deste estudo. 


\section{Referências}

1. Veras MASM, Calazans GJ, Ribeiro MCSA, Oliveira CAF, Giovanetti MR, Facchini R, França IL, McFarland W. High HIV prevalence among men who have sex with men in a time-location sampling survey, São Paulo, Brazil. AIDS and Behavior 2015; 19(9):15891598.

2. Illouz E. Consuming the romantic utopia: love and the cultural contradictions of capitalism. Berkeley: University of California Press; 1997.

3. Illouz E. Romance and rationally on the internet. Washington: American Sociological Association; 2006.

4. Illouz E. Why love hurts? A sociological explanation. London: Polity Press; 2012.

5. Illouz E. Hard core romance: "fifty shades of grey", bes$t$-sellers and society. Chicago: University of Chicago Press; 2014.

6. Miskolci R. Desejos digitais: uma análise sociológica da busca por parceiros on-line. Belo Horizonte: Autêntica; 2017.

7. Pelúcio L, Miskolci R. A prevenção do desvio: o dispositivo da AIDS e a repatologização das sexualidades dissidentes. Sexualidad, Salud y Sociedad 2009; (1):125-157.

8. Dourado I, Veras MASM, Barreira D, Brito AM. Tendências da epidemia de Aids no Brasil após a terapia anti-retroviral. Rev Saude Publica 2006; 40(Supl.):917.

9. Creswell JW. Projeto de pesquisa: métodos qualitativo, quantitativo e misto. Porto Alegre: Artmed; 2007.

10. Oliveira FL. Triangulação metodológica e abordagem multimétodo na pesquisa sociológica: vantagens e desafios. Ciências Sociais Unisinos 2015; 51(2):133-143.

11. Adelman M, Franco CB, Pires AF. Ruralidades atravessadas: jovens do meio campeiro e narrativas sobre o eu e o(s) outro(s) nas redes sociais. Cadernos Pagu 2015; (44):141-170.

12. Brasil. Ministério da Saúde (MS). Conselho Nacional de Saúde. Resolução no 466, de 12 de dezembro de 2012. Diário Oficial da União 2013; $13 \mathrm{dez}$.

13. Fry P. Da hierarquia à igualdade. In: Fry P, organizador. Para inglês ver: identidade e politica na cultura brasileira. Rio de Janeiro: Zahar; 1982. p. 87-115.

14. Green JN, Trindade R. Homossexualismo em São Paulo e outros escritos. São Paulo: Ed. Unesp; 2005.

15. Guimarães CD. O homossexual visto por entendidos. Rio de Janeiro: Garamond; 2004.

16. Perlongher NO. O negócio do michê: prostituição viril em São Paulo. São Paulo: Brasiliense; 1987.

17. Simões JA, França IL, Macedo M. Jeitos de corpo: cor/ raça, gênero, sexualidade e sociabilidade juvenil no centro de São Paulo. Cadernos Pagu 2010; (35):37-78.

18. Zago LF. Os meninos: corpo, gênero e sexualidade através de um site de relacionamentos [tese]. Porto Alegre: Universidade Federal do Rio Grande do Sul; 2013.
19. Butler J. Problemas de gênero: feminismo e subversão da identidade. Rio de Janeiro: Civilização Brasileira; 2003.

20. Mowlabocus S. Gaydar culture: gay men, technology and embodiment in the digital age. Farnham, Burlington: Ashgate; 2010.

21. Kurashigue KD. Negociando diferenças online: notas sobre interações homoeróticas em salas de bate-papo na cidade de São Carlos. São Carlos: mimeo; 2015.

22. Miskolci R. San Francisco e a nova economia do desejo. Lua Nova: Revista de Cultura e Política 2014; (91):269-295.

23. Race K. Engaging in a culture of barebacking: gay men and the risk of HIV prevention. In: Hannah-Moffat K, O’Malley P, organizadores. Gendered risks. Londres: Glass House Press; 2007. Cap. 5.

24. Ferraro AR. Analfabetismo e níveis de letramento no Brasil: o que dizem os censos? Educ. Social 2002; 23(81):21-47.

25. Instituto Brasileiro de Geografia e Estatística (IBGE). Sintese de indicadores sociais: uma análise das condições de vida da população brasileira. Brasília: IBGE Coordenação de População e Indicadores Sociais; 2017.

26. Baym N. Personal connections in the digital age. Cambridge: Polity Press; 2010.

27. Sibilia P. O show do Eu: a intimidade como espetáculo. Rio de Janeiro: Nova Fronteira; 2008.

28. Lauretis T. Technologies of gender: essays on theory, film, and fiction. Bloomington: Indiana University Press; 1987.

29. Beleli I. O imperativo das imagens: construção de afinidades nas mídias digitais. Cadernos Pagu 2015; (44):91-114.

30. Miskolci R. "Discreet and out of the gay scene" notes on contemporary sexual visibility. Cadernos Рagu 2015; (44):61-90.

31. Pollak M. Os homossexuais e a AIDS: sociologia de uma epidemia. São Paulo: Estação Liberdade; 1990.

32. Perlongher NO. O que é Aids. São Paulo: Brasiliense; 1987.

33. Gilman S. Disease and representation: images of illness from madness to AIDS. New York: Cornell University Press; 1991.

Artigo apresentado em 27/05/2018

Aprovado em 23/07/2018

Versão final apresentada em 25/07/2018 